\title{
Concepções de Matemática de Alunas-Professoras dos Anos Iniciais
}

\author{
Reginaldo Fernando Carneiro' \\ Cármen Lúcia Brancaglion Passos"
}

'Universidade Federal de Juiz de Fora (UFJF), Juiz de Fora/MG - Brasil "Universidade Federal de São Carlos (UFSCAR), São Carlos/SP - Brasil

RESUMO - Concepções de Matemática de Alunas-Professoras dos Anos Iniciais. Este artigo tem como objetivo discutir as concepções sobre matemática de alunas-professoras dos anos iniciais do Ensino Fundamental de um curso de Pedagogia à distância, no qual realizamos uma pesquisa qualitativa durante o trabalho nas disciplinas referentes à matemática. As atividades virtuais ali desenvolvidas geraram dados cuja análise evidenciou alguns aspectos da concepção de matemática como resolução de problemas. Tal análise também enfatizou a necessidade de pautar o ensino na compreensão e na justificativa das fórmulas, dos procedimentos e dos algoritmos. Além disso, apontou que as alunas-professoras refletiram e problematizaram suas concepções.

Palavras-chave: Concepções. Matemática. Ensino e Aprendizagem.

ABSTRACT - Mathematical Conceptions of the Elementary School Student-Teachers. This paper aims to discuss the conceptions about mathematics of the Elementary School student-teachers of a Pedagogy distance learning course, in which we performed a qualitative research while working in the disciplines related to mathematics. The virtual activities generated data which analysis revealed some aspects of mathematics conception as problem solving. It also emphasized the need to guide the teaching in the understanding and rationale of formulae, procedures, and algorithms. In addition, it pointed out that the student-teachers had reflected on and problematized their conceptions.

Keywords: Conceptions. Mathematics. Teaching and Learning.

Educação \& Realidade, Porto Alegre, v. 39, n. 4, p. 1113-1133, out./dez. 2014.1113 Disponível em: <http://www.ufrgs.br/edu_realidade> 
Concepções de Matemática de Alunas-Professoras dos Anos Iniciais

\section{Introdução}

Este artigo, um recorte da pesquisa de doutorado do primeiro autor, tem como objetivo discutir as concepções sobre matemática de alunas-professoras dos anos iniciais do Ensino Fundamental de um curso de Pedagogia à distância.

As participantes da pesquisa - Alice, Ana, Andréia, Branca, Kerusca, Lusmarina, Renata e Su - são denominadas de alunas-professoras, pois eram estudantes do curso de Pedagogia e já atuavam como docentes.

As discussões sobre as concepções de matemática estão pautadas em excertos das atividades virtuais das disciplinas referentes ao ensino e à aprendizagem da matemática do curso: linguagens matemáticas 1 - LM1 - e linguagens matemáticas 2 - LM2, cujos objetivos são possibilitar aos alunos conhecer e analisar a realidade escolar em seus processos de ensinar e aprender matemática e perceber o que a influencia; caracterizar e analisar a situação do ensino de matemática nos anos iniciais do Ensino Fundamental; e conhecer e analisar alternativas metodológicas do ensino de matemática que considerem a realidade escolar dos anos iniciais do Ensino Fundamental.

Na disciplina LM1, com carga horária de 60 horas, foram abordados aspectos teóricos e metodológicos relacionados à: natureza do conhecimento matemático; função da matemática no Ensino Fundamental; conteúdos matemáticos ensinados nos anos iniciais; e sistema de numeração decimal e operações fundamentais. Em LM2, também com 60 horas de carga horária, abordaram-se os seguintes conteúdos: espaço e forma, grandezas e medidas, frações, pensamento estocástico e algumas considerações sobre a matemática na Educação Infantil.

As principais atividades desenvolvidas nas disciplinas foram a elaboração de textos individuais e coletivos e a discussão em fórum. LM1 e LM2 tinham a finalidade de levar os estudantes a vivenciarem a prática da pesquisa em educação matemática e os fundamentos da matemática.

A primeira atividade de LM1 foi a escrita de uma narrativa sobre as lembranças das alunas-professoras com relação à matemática durante sua trajetória escolar, com o objetivo de apreender as concepções de matemática. Nessas narrativas, as alunas-professoras conceberam a matemática como abstrata, a-histórica, imutável, pronta e acabada. Desse modo, os conceitos são descobertos e não criados, nem inventados pelo homem. A matemática, nessa perspectiva, se reduz ao cálculo, só existem o erro e o acerto na resolução dos exercícios, ou seja, foca-se o produto final e não o processo; portanto apenas poucos, considerados gênios, podem aprendê-la. Além disso, o ensino se pauta na reprodução e, por isso, os alunos precisam repetir e memorizar fórmulas, procedimentos e algoritmos. Assim, devem decorar a tabuada e aplicar mecanicamente fórmulas e algoritmos.

1114 Educação \& Realidade, Porto Alegre, v. 39, n. 4, p. 1113-1133, out./dez. 2014. Disponível em: <http://www.ufrgs.br/edu_realidade> 
As lembranças das alunas-professoras apresentadas nas narrativas podem levar a dificuldades e a bloqueios com relação ao ensino e à aprendizagem da matemática e gerar conflitos. Assim, as disciplinas LM1 e LM2 buscaram problematizar e levá-las a refletir sobre suas concepções e as culturas de aulas de matemática que vivenciaram durante toda sua trajetória escolar.

A partir do exposto, inicialmente apresentaremos o referencial teórico que pautou as discussões e análises. Depois, realizaremos uma discussão sobre a metodologia e os caminhos percorridos no estudo. Em seguida, apresentaremos e discutiremos os dados e, por fim, traremos algumas considerações.

\section{Concepções de Matemática: uma discussão teórica}

Assim como Nacarato, Mengali e Passos (2009), compreendemos que é difícil definir "concepção”, por ser um conceito polissêmico. Pesquisadores que investigaram essa temática atribuem a esse termo diferentes características e conotações: alguns autores fazem a distinção entre concepções e crenças, outros usam esses dois termos como sinônimos, ou como sinônimo de visões, ou ainda incluem as concepções e as crenças no sistema de conhecimentos dos professores.

Por isso, neste texto, apropriamo-nos do conceito de Thompson (1992), que compreende concepção como uma estrutura mental mais geral, que abrange concepções, conceitos, significados, proposições, regras, imagens mentais, preferências e gostos.

Estudos evidenciaram que os professores tratam suas concepções como conhecimentos, porém, a pesquisadora Alba Thompson (1992) destacou algumas características que os distinguem: as concepções podem ser defendidas em diversos níveis de convicção, independem de sua validade e não são consensuais, ou seja, pessoas diferentes pensam de forma diferente; o conhecimento, porém, está associado à certeza e à veracidade.

Ainda para essa autora (Thompson, 1992, p. 130), o conhecimento é um “[...] consentimento geral sobre procedimentos para avaliar e julgar suas validades e deve ter critérios envolvendo princípios de evidência”. Por outro lado, as concepções são geralmente "baseadas em justificativas por razões que não têm critérios e, portanto, são caracterizadas por falta de concordância pela qual elas devem ser avaliadas e julgadas".

Nesse contexto, o conjunto das concepções de um indivíduo forma um sistema que não é estático, imutável, mas dinâmico, podendo sofrer mudanças e reestruturações decorrentes de suas experiências.

As concepções são essencialmente cognitivas e funcionam como um filtro. De acordo com Ponte (1992, p. 1), “[...] por um lado, são indispensáveis, pois estruturam o sentido que damos às coisas. Por outro lado, atuam como bloqueador em relação a novas realidades ou certos

Educação \& Realidade, Porto Alegre, v. 39, n. 4, p. 1113-1133, out./dez. 2014.1115 Disponível em: <http://www.ufrgs.br/edu_realidade> 
Concepções de Matemática de Alunas-Professoras dos Anos Iniciais

problemas, limitando nossas possibilidades de atuação e compreensão".

Ainda para esse autor, as concepções não se reduzem a aspectos do comportamento que podem ser observados, mas que não se revelam com facilidade. Assim, elas podem não ser facilmente apreendidas e, nos processos de ensino-aprendizagem, a influência do que os professores compreendem como matemática, muitas vezes, pode criar obstáculos para seu desempenho docente.

As concepções se formam em um processo simultaneamente individual e social, e, em cada indivíduo, elas se constituem tanto por suas experiências pessoais e por sua história de vida como pela relação que ele estabelece com as outras pessoas. Nessa perspectiva, nossas concepções sobre matemática são influenciadas por nossas experiências e também pelas representações sociais dominantes (Ponte, 1992). Portanto, atuam sobre elas nossos contatos com os professores que tivemos durante a vida escolar, a forma como ensinavam, as relações que elaboramos com os conteúdos, quando estudantes etc.

Embora as concepções dos docentes possam influenciar sua prática pedagógica, há vários graus de consistência nessa relação. Para esse autor (1992), as concepções influenciam a prática, na medida em que apontam os caminhos e as decisões a serem tomadas. Por outro lado, a prática proporciona a geração de concepções que sejam compatíveis com elas e que sirvam para enquadrá-las conceitualmente. Nesse sentido, as concepções e a prática retroalimentam-se, em um movimento de ida e vinda, de forma a umas adequarem-se às outras. As concepções influenciam as práticas, no sentido de apontar caminhos e embasar as decisões. E as práticas geram concepções que sejam compatíveis com elas e que as possam fundamentar conceitualmente.

A partir do exposto, Chacón (2000) propõe três tipos de concepções sobre a matemática: matemática como uma caixa de ferramentas (concepção utilitarista), em que se busca criar instrumentos para o desenvolvimento de técnicas e de outras ciências; matemática como um corpo estático e unificado de conhecimentos (concepção platônica), em que há a descoberta e não a criação; e matemática como um campo de criação humana (concepção de resolução de problemas), no qual se geram modelos e procedimentos que permanecem abertos à revisão.

Nesse mesmo sentido, Ponte (1992) explicita algumas concepções dos professores, que compreendemos poderem ser enquadradas na concepção utilitarista e platônica de matemática discutida por Chacón (2000).

O cálculo é a parte mais substancial da matemática. Para Ponte (1992), o cálculo é muito importante e não se pode menosprezá-lo, mas relacionar a matemática a cálculos seria reduzi-la a um dos aspectos mais pobres e de menor valor, pois, com as calculadoras e os computadores, não são requeridas capacidades especiais de raciocínio para essa tarefa.

1116 Educação \& Realidade, Porto Alegre, v. 39, n. 4, p. 1113-1133, out./dez. 2014. Disponível em: <http://www.ufrgs.br/edu_realidade> 
A Matemática é formal, rigorosa, e não permite espaço para o erro, a incerteza, a dúvida. No entanto, "[...] a prática da matemática, como produto humano, está sujeita às imperfeições naturais da nossa espécie. Nela há margem para se desenvolverem diversos estilos ou se tomarem diferentes opções” (Ponte, 1992, p. 16).

A Matemática está desligada da realidade e, quanto mais abstrata e pura, melhor seria a matemática escolar. Assim, não se considera o processo histórico em que ela se desenvolve; nem se questiona se ela é compreensível aos estudantes ou se seu ensino corresponde ou não à sua relevância social.

Em matemática a criatividade e o novo somente são possíveis para os gênios. Contudo, para Ponte (1992, p. 16, grifo do autor), “[...] é possível valorizar as investigações e descobertas das pessoas normais”.

Nesse contexto, as investigações (Serres, 2010; Vignoto; Moraes, 2013) apontam as características das três concepções explicitadas por Chacón (2000).

O estudo de Serres (2010) teve como finalidade analisar a forma como 12 professoras conceberam e praticaram o ensino de matemática no decorrer das interdisciplinas - disciplinas que buscam articular conhecimentos específicos, teóricos e práticos - de um curso de Pedagogia a distância. A pesquisa de natureza qualitativa pautou-se em um estudo de caso, e os instrumentos para a produção dos dados foram as postagens das participantes, contendo suas reflexões sobre as atividades realizadas e seus portfólios de aprendizagem. O estudo apontou algumas características de concepção de matemática, seu ensino e sua aprendizagem, na perspectiva da resolução de problemas.

Segundo a pesquisadora, as interdisciplinas fizeram com que os participantes concebessem o ensino de matemática de forma que os estudantes sejam agentes de seu próprio aprendizado e o papel do professor seja conhecer seus alunos e propor a eles atividades em que possam agir sobre a realidade. Além disso, o curso buscou desestabilizar as certezas dos participantes da investigação, no sentido de repensar sobre suas concepções. Em razão de ser um curso a distância, esse processo ocorreu em tempos diferentes para cada um.

Vignoto e Moraes (2013) tiveram como objetivo investigar as atividades mais comuns realizadas pelas crianças no primeiro ano do Ensino Fundamental, a fim de compreender como o ensino de matemática é desenvolvido nesse nível de escolarização. Para tanto, as pesquisadoras tomaram como fonte de produção de dados os cadernos dos alunos de escolas municipais. Os resultados evidenciaram a predominância de atividades do bloco Números e Operações, em especial, o trabalho com os signos numéricos, o que revela uma concepção de ensino da matemática que prioriza alguns conteúdos, em detrimento de outros, como por exemplo, a geometria.

Educação \& Realidade, Porto Alegre, v. 39, n. 4, p. 1113-1133, out./dez. 2014 
Concepções de Matemática de Alunas-Professoras dos Anos Iniciais

Expostos os nossos fundamentos teóricos, passaremos agora a apresentar alguns aspectos referentes ao desenvolvimento da pesquisa.

\section{Os Caminhos da Pesquisa}

Segundo Fiorentini e Lorenzato (2006, p. 60), a pesquisa é “[...] um processo de estudo que consiste na busca disciplinada/metódica de saberes ou compreensões acerca de um fenômeno, problema ou questão da realidade ou presente na literatura o qual inquieta/instiga o pesquisador perante o que se sabe ou diz a respeito". Para discutir as concepções sobre matemática de professoras dos anos iniciais do Ensino Fundamental, alunas de um curso a distância de Pedagogia, optamos pela abordagem qualitativa (Bogdan; Biklen, 1994; Lüdke; André, 1986).

Nesse contexto, fizemos um primeiro contato por $e$-mail com os 152 estudantes que ingressaram em 2007 no curso de Pedagogia à distância, a fim de verificar sua possibilidade e sua disponibilidade para participação na pesquisa. Esses alunos já haviam cursado a disciplina de Linguagens Matemáticas 1 (abril a maio de 2010) e estavam participando de Linguagens Matemáticas 2 (setembro a outubro de 2010). Recebemos o retorno de 61 estudantes que demonstraram interesse em participar da investigação.

Depois da autorização pelo Comitê de Ética da Universidade, encaminhamos, via $e$-mail, questionários de caracterização para os alunos que haviam respondido positivamente ao convite da mensagem inicial. Nesse questionário constavam perguntas sobre a formação dos estudantes, sua atuação profissional, assim como, caso fosse docente, sobre a rede de ensino em que atuavam, sua carga horária e seu tempo de experiência.

Recebemos o retorno de 32 questionários, dentre os quais 8 eram de alunas que já atuavam como docentes nos anos iniciais do Ensino Fundamental. Optamos pela participação apenas dessas 8 professoras na investigação porque elas já tinham o contato com a sala de aula, ensinavam os conteúdos matemáticos e eram licenciandas no curso de Pedagogia. Escolheram o nome pelo qual seriam identificadas na pesquisa sendo que algumas preferiram um nome fictício e outras optaram pelo seu próprio nome: Alice, Ana, Andréia, Branca, Kerusca, Lusmarina, Renata e Su.

Compreendemos que as vivências das alunas-professoras nas disciplinas relacionadas à matemática do curso de Pedagogia à distância podem ter se configurado como processos formativos que contribuíram para refletirem e problematizarem suas concepções de matemática e proporcionaram a elas a aprendizagem de conteúdos matemáticos e aprendizagens da docência, pois as atividades propostas podem ter promovido à compreensão, a (re)significação e a (re)construção dos conhecimentos matemáticos, por meio das interações e das mediações,

1118 Educação \& Realidade, Porto Alegre, v. 39, n. 4, p. 1113-1133, out./dez. 2014 Disponível em: <http://www.ufrgs.br/edu_realidade> 
no ambiente virtual, entre os diferentes atores, configurando-se como espaços formativos.

Neste texto, para a produção de dados, utilizamos as atividades virtuais realizadas pelas alunas-professoras nas disciplinas LM1 e LM2.

Os excertos das participantes aqui transcritos são identificados com seu nome, podendo haver trechos com mais de um nome, pois algumas atividades virtuais foram realizadas coletivamente. Indicamos o tipo de atividade a que se refere o trecho: Fórum de discussão, Texto individual e Wiki; as iniciais da disciplina - LM1, LM2; as atividades realizadas nas disciplinas, AIII-1, reportando-se à primeira atividade da unidade 3 do material, ou ainda, AI-3, referindo-se à terceira atividade da unidade 1 .

A análise dos dados, momento de organização e reflexão sistemática com o intuito de compreender o fenômeno estudado, foi um processo difícil e complexo, que exigiu esforço do investigador, no sentido de debruçar-se sobre os dados durante certo período de tempo. Esse processo implicou a realização de várias leituras do material, sem saber a princípio aonde chegaríamos, tendo sido necessárias, para isso, muitas idas dos dados ao referencial teórico e vindas do referencial aos dados.

A análise dos dados, de acordo com Fiorentini e Lorenzato (2006, p. 133), é “[...] um processo trabalhoso e meticuloso que implica múltiplas leituras do material disponível, tentando nele buscar unidades de significação ou, então, padrões e regularidades para, depois agrupá-las em categorias". Para essa análise, pautamo-nos na perspectiva de análise de conteúdo que se refere a:

[...] um conjunto de técnicas de análise de comunicações visando obter por procedimentos sistemáticos e objetivos de descrição do conteúdo das mensagens indicadores (quantitativos ou não) que permitam a inferência de conhecimentos relativos às condições de produção/recepção (variáveis inferidas) destas mensagens (Bardin 1977, p. 44).

Para a autora, a codificação consiste no tratamento do material bruto, seguindo regras precisas, em que, a partir de recorte, agregação e enumeração, se consegue chegar a uma representação do conteúdo. Nesse processo, é necessário fazer o recorte a partir da escolha de unidades - registro ou contexto. A unidade de registro é a unidade base que auxilia na categorização. Optamos, na pesquisa, pela análise a partir da unidade de registro tema, pois pode ser utilizada para investigar motivações, opiniões, crenças, concepções, atitudes, valores, tendências, entre outros. Então, procedemos à categorização, que consiste na classificação dos elementos, por analogia, de maneira a formar um conjunto, agrupando as mensagens a partir de critérios predeterminados.

Realizamos a categorização pelo aspecto semântico, ou seja, partimos de categorias temáticas, pois verificamos muitas aproximações com relação a diversos temas, o que fez emergir as categorias.

Educação \& Realidade, Porto Alegre, v. 39, n. 4, p. 1113-1133, out./dez. 2014.1119

Disponível em: <http://www.ufrgs.br/edu_realidade> 
Concepções de Matemática de Alunas-Professoras dos Anos Iniciais

A categoria Relações com a matemática, seu ensino e sua aprendizagem dividiu-se em cinco subcategorias: concepções sobre a matemática; concepções sobre o ensino de matemática; sentimentos em relação à matemática; práticas engessadas de ensinar matemática; e relação professor-aluno. Neste texto, focamos as discussões na primeira subcategoria.

Essa categorização temática foi realizada por meio da organização dos dados em tabelas. Nesse processo, foi necessário compor e recompor as possíveis categorias de análise. Inicialmente havia muitas tabelas, que foram reagrupadas, considerando seus temas. Alguns dados foram retirados e outros acrescentados. Além disso, mesmo durante a apresentação dos dados e a análise, as categorias foram se reconfigurando. Esse é o movimento da pesquisa, e o investigador, a princípio, está caminhando por um terreno arenoso, que vai se tornando mais firme com o aprofundamento e a imersão nos dados.

Esse encaminhamento nos permitiu trazer aqui uma discussão sobre as concepções de matemática das alunas-professoras.

\section{Concepções de Matemática das Alunas-Professoras}

No fórum de discussão da unidade 2 de LM1, as alunas-professoras relataram entender a matemática como uma forma de constituição da cidadania. Para Branca, a matemática, como uma atividade humana, é fundamental na constituição do cidadão, principalmente, na sociedade atual em que vivemos.

Vejo a matemática e o seu ensino como algo essencial, uma vez que, vista como uma atividade humana, esta é imprescindível para a construção da cidadania, ainda mais no mundo moderno e capitalista em que vivemos atualmente, que exige que sejamos e tenhamos um raciocínio rápido e lógico, até mesmo porque este é utilizado por muitas áreas do conhecimento (Branca, Fórum de discussão, LM1 - AII-1).

Segundo expressou Ana, ao dialogar com a Aluna 13, o ensino de matemática deve ser democrático, sendo a escola e os professores responsáveis pela formação de sujeitos críticos.

Ana: Cabe à escola trabalhar de forma democrática a matemática e as demais disciplinas curriculares, a fim de que seus alunos e alunas apropriem-se de seus saberes de forma significativa, reflexiva e construtiva, não alienante/passiva, pois se assim for, estaremos formando pessoas e profissionais diversos às reais necessidades sociais e culturais das nossas sociedades. Somos responsáveis pelo mundo que estamos agora produzindo ou reproduzindo.

Aluna 13: Ana,

Quando você diz que a escola deve trabalhar de forma democrática a matemática e as demais disciplinas, acho importante acrescentar que esse trabalho seja interdisciplinar. Explico: no material da disciplina consta

1120 Educação \& Realidade, Porto Alegre, v. 39, n. 4, p. 1113-1133, out./dez. 2014. Disponível em: <http://www.ufrgs.br/edu_realidade> 
que para que o estudante tenha compreensão sobre um assunto da matemática, é necessário que tal assunto tenha sentido para ele. Como o currículo da matemática lida como uma série de assuntos que não possuem vínculo com a vida diária dos estudantes, como também vemos no material, é necessário que a matemática dialogue com outras disciplinas, de modo que o aluno mais facilmente atribua um sentido para aquilo que está aprendendo (Fórum de discussão, LM1 - AII-1, grifo da aluna).

Destacamos, na postura de Ana, a clareza em perceber que o modo como os estudantes são formados implica a elaboração da concepção de mundo, quer no sentido de produção desse mundo, se essa formação for crítica e reflexiva; quer na reprodução, se for passiva e alienante, o que não está de acordo com as necessidades sociais e culturais da sociedade atual. Nessa perspectiva, a Aluna 13, que dialogou com Ana, ressaltou a importância de relacionar os conteúdos matemáticos às outras áreas de conhecimento, de forma que o estudante atribua sentido a eles.

Branca e Ana explicaram em que sentido a matemática pode contribuir para formar cidadãos. Ana explicitou: "Precisamos formar cidadãos pensantes, atuantes, críticos e livres. Despertar, através das atividades matemáticas, sentimentos de solidariedade, de colaboração, de participação social e de respeito às diferenças, sejam elas de opinião, de ideias, ou de capacidades" (Fórum de discussão, LM1 - AII-1).

Nas palavras de Branca,

[...] para exercer a cidadania, é necessário saber calcular, medir, raciocinar, argumentar, tratar informações, uma vez que estamos à mercê de situações inesperadas. Assim também acontece com a matemática, que nos apresenta situações imprevistas, inesperadas. Todavia são necessárias tomadas de decisões, e essas exigem criatividade e ética, e a matemática é um instrumento importantíssimo para a tomada de decisões (Fórum de discussão, LM1 - AII-1).

Nessa perspectiva, a matemática é considerada pelas alunas-professoras como fundamental para desenvolver o senso crítico e reflexivo dos alunos, sendo necessário, para tanto, compreender diversos conceitos matemáticos.

Branca também destacou a matemática como constituição da cidadania, mas no excerto indicou um aspecto utilitarista: utilização de conteúdos matemáticos em outras áreas do conhecimento. Assim, podemos perceber que, por um lado, ela afirma uma característica da concepção de matemática como resolução de problemas, mas, por outro, ainda foca o utilitarismo.

Ponte (1992, p. 25) denominou de concepções manifestas aquelas explicitadas verbalmente pelos professores e concepções ativas as que, de fato, informam a prática. Ressalta que as manifestas “[...] podem sofrer uma influência significativa do que no discurso social e profissional é tido como adequado, mas não serem parcial ou integralmente capazes de informar a prática”. Ampliando essa ideia, o professor pode

Educação \& Realidade, Porto Alegre, v. 39, n. 4, p. 1113-1133, out./dez. 2014. 1121 Disponível em: <http://www.ufrgs.br/edu_realidade> 
Concepções de Matemática de Alunas-Professoras dos Anos Iniciais

mencionar uma concepção a partir do que é considerado adequado socialmente, como no caso apresentado por Branca na discussão, mas, por outro lado, pode ter inconscientemente, vestígios de sua concepção ativa.

Dessa forma, concepções que pertencem aos diferentes paradigmas de matemática podem conviver juntas no sistema de concepções do indivíduo, pois tal sistema não é constituído de limites e fronteiras bem definidos, ou seja, não envolve concepções pertencentes a apenas um desses paradigmas.

Por fim, essa concepção de matemática, evidenciada nos excertos das alunas-professoras, indica possibilidades de promover nos estudantes o desenvolvimento da criatividade; da reflexão; da tomada de decisão; de sentimentos como o respeito às diferenças; da solidariedade, além de formar sujeitos atuantes, pensantes, criativos e críticos.

Analisamos reflexões sobre as concepções do ensino de matemática e, dentre elas, destacamos algumas práticas das alunas-professoras, ao buscarem alternativas para romperem com práticas engessadas com que tiveram contato em suas trajetórias escolares e, por vezes, também em algum momento de suas práticas docentes.

Alice e Renata relataram, no texto coletivo elaborado na $w i k i^{1}$, que a memorização era muito valorizada, mas que não é mais suficiente atualmente, quando se deve enfocar a argumentação e a exploração.

Nas décadas passadas o processo de memorização era supervalorizado [...], a contextualização da álgebra praticamente não aparecia no ensino dos conteúdos matemáticos. E, embora, tal modo de se ensinar matemática tenha tido sua validade, atualmente a mera ênfase na memorização e nas técnicas operatórias se apresentam insuficientes para atender às exigências da Sociedade da Informação. [...] A memorização é necessária, mas, isolada, estagna a aprendizagem do aluno (Alice, Renata, wiki, LM1 - AIV-3).

As alunas-professoras relataram que, para romper com a memorização e com a reprodução de técnicas e de procedimentos, aspectos da concepção de matemática platônica e utilitarista, os docentes precisam utilizar diferentes metodologias, que não tenham como foco esses elementos e que se pautem na justificativa e na compreensão, buscando enfatizar a matemática como criação humana, dinâmica, em constante evolução.

A resolução de problemas, a história da matemática, os jogos e a investigação matemática são algumas dessas metodologias, que podem ser utilizadas no ensino de matemática, pois focam a argumentação; a descoberta; a exploração; e a investigação, características que devem estar presentes nas aulas de matemática.

Contudo, é interessante destacar que as alunas-professoras não descartam a importância da memorização, mas que, atualmente, não é mais suficiente reduzir a matemática a esse elemento.

1122 Educação \& Realidade, Porto Alegre, v. 39, n. 4, p. 1113-1133, out./dez. 2014 Disponível em: <http://www.ufrgs.br/edu_realidade> 
Su apontou, em um fórum de discussão, que o ensino de matemática, a partir da resolução de problemas, possibilita a tomada de decisão para resolver problemas, tanto na própria matemática como no cotidiano.

O ensino da matemática ajuda a formar cidadãos críticos e participativos, pois as resoluções de problemas tornam os indivíduos mais confiantes e participativos, levando-os a usar o raciocínio e com isso tornando os indivíduos mais confiantes e capazes de descobrir os vários caminhos que a matemática possibilita para a solução de problemas, tanto na matemática como para sua vida cotidiana (Fórum de discussão, LM1 - AII-1).

Formar sujeitos críticos pode vir a auxiliá-los a resolver situações-problema do cotidiano, como exemplificou Ana em,

[...] decidir sobre uma questão pessoal, profissional, enfim, resolver uma problemática no trânsito, no bairro onde mora, na saúde de seu município, resolver um problema familiar, são exemplos de questões que necessitarão de elementos que aprendemos com a matemática e que fazem parte também da nossa realidade (Fórum de discussão, LM1 - AII-1).

É interessante a colocação de Su, que afirmou que essa concepção de matemática possibilita a resolução de problemas não só dentro da própria matemática, mas também relacionados ao cotidiano, sem focar apenas neste último, pois, nesse caso, teríamos uma característica do utilitarismo dessa área de conhecimento. Esse aspecto amplia a concepção de ensino de matemática de muitos professores de que as atividades propostas devem basear-se apenas na realidade do aluno e inclui também a resolução de problemas na própria matemática.

Esses aspectos permitem pensar na matemática como falível, inacabada, incompleta, o que é uma alternativa para promover mudanças na prática do professor e uma maneira de amenizar os traumas e a aversão provocada pelas práticas engessadas de ensino de matemática que as alunas-professoras tiveram durante sua trajetória escolar.

Além disso, algumas delas explicitaram, em diferentes atividades virtuais, que trabalhavam com os alunos em grupos, rompendo a ideia de trabalhar individualmente, com os alunos sentados em filas, um atrás do outro. Como destaca Viñao Frago (1998, p. 175), “[...] a análise histórica das modalidades de organização e disposição de pessoas e objetos na sala de aula, mostra sua relação com o sistema ou método pedagógico seguido".

Nesse sentido, a concepção de matemática das alunas-professoras é evidenciada em outra perspectiva, diversa daquela que tiveram em sua trajetória escolar, que enfatizava a reprodução, a memorização de fórmulas e algoritmos, em que as aulas eram, via de regra, fundamentadas na exposição dos conteúdos pelo professor, a organização da sala de aula colocava os estudantes sentados individualmente, um atrás do outro, pois, para que aprendessem, era necessário que ouvissem as

Educação \& Realidade, Porto Alegre, v. 39, n. 4, p. 1113-1133, out./dez. 2014.1123 Disponível em: <http://www.ufrgs.br/edu_realidade> 
Concepções de Matemática de Alunas-Professoras dos Anos Iniciais

explicações do professor e ficassem em silêncio, o que não acontece no trabalho em grupo, quando eles conversam, trocam ideias, buscam argumentar sobre suas estratégias para a resolução de uma atividade. Esse burburinho, na perspectiva apontada, é sinal de indisciplina e, portanto, deve ser evitado a todo custo. Além da disposição dos estudantes, é fundamental que a mesa do professor esteja no centro e à frente da sala, pois ele é o centro do processo de ensino e aprendizagem, ele transmite seus conhecimentos e os estudantes recebem passivamente as informações.

Andréia, em um fórum de discussão sobre geometria, comentou que brincadeiras e obras de arte podem ser utilizadas no ensino de matemática. Ela explica que a amarelinha é uma brincadeira que pode ser explorada com as crianças, como também é possível ensinar geometria a partir de obras de arte, como as do pintor Volpi, que utiliza figuras geométricas em seus quadros.

Durante o período de observação que realizei nas escolas de Educação Infantil também pude notar a aproximação entre geometria e a obra do pintor Volpi que utiliza-se de formas geométricas para compor alguns de seus quadros. Também observei uma aproximação com brincadeiras como a amarelinha. Também algumas oficinas de confecção de brinquedos a partir de embalagens (Fórum de discussão, LM2 - AI-2).

As alunas-professoras refletiram também sobre vários conceitos geométricos e algumas possibilidades do ensino de geometria que, como destaca o material utilizado nas disciplinas LM1 e LM2, deve pautar-se na observação, na manipulação, na comparação e na classificação. Kerusca destacou que os brinquedos permitem iniciar, com as crianças, o desenvolvimento das ideias geométricas ainda antes da escolarização.

Andréia relatou que, durante o estágio, percebeu que o ensino pode acontecer por meio das obras de Volpi e também da Amarelinha, brincadeira utilizada na regência de Renata durante o Estágio Supervisionado e que, segundo esta, possibilitou trabalhar com conteúdos de geometria, como retângulo e semicírculo.

No ensino de geometria, afirmou Su, é importante que as crianças experimentem e manipulem materiais, para desenvolver:

[...] ideias geométricas e estruturas conceituais mais complexas através da exploração de blocos lógicos, papel quadriculado, desenhos, classificação das figuras planas e não planas, dobrar, recortar, classificar, construir, transformar e usar espelhos para trabalhar linhas de simetria (Texto individual, LM2 - AI-1).

Kerusca evidenciou que a geometria começa a fazer parte da vida da criança desde muito cedo e pode ser trabalhada por meio de,

[...] brinquedos com formas geométricas onde as crianças brincam como um quebra-cabeça, procurando o local certo que cada forma geométrica

1124 Educação \& Realidade, Porto Alegre, v. 39, n. 4, p. 1113-1133, out./dez. 2014 Disponível em: <http://www.ufrgs.br/edu_realidade> 
pertence. Dessa forma, podemos afirmar que a criança mesmo que involuntária possui conhecimento do universo geométrico quando adentra a escola, o que facilita por um lado o trabalho do docente (Fórum de discussão, LM2 - AI-2).

É importante destacar essas discussões sobre geometria, pois essa é uma área da matemática que, por um longo período, esteve em segundo plano no ensino, em que eram enfatizados apenas os números e as operações.

Lorenzato (1995) atribui o abandono do ensino de geometria, principalmente, a duas razões: professores que, desprovidos de conhecimentos de geometria, tendem a não ensiná-la; dependência dos livros didáticos, que traziam esse conteúdo no final, o que os deixava para serem ensinados no fim do ano letivo. Dessa forma, a geometria, apresentada superficialmente, desligada da realidade, não integrada às outras disciplinas, e nem mesmo às outras áreas da matemática, "[...] a mais bela página do livro dos saberes matemáticos, tem recebido efetiva contribuição por parte dos livros didáticos para que ela seja realmente preterida na sala de aula" (Lorenzato, 1995, p. 4).

Esses aspectos aqui reportados, em que aparecem a brincadeira e a obra de arte como possibilidades de abordar os conteúdos geométricos, parecem demonstrar a preocupação das professoras com a geometria e sua intenção de integrar o ensino dessa área da matemática a outras disciplinas e à realidade.

Lusmarina, ao discutir o jogo Avançando com o Resto ${ }^{2}$ em um texto elaborado na wiki, destacou o erro como uma forma de aprendizagem e a criação das próprias estratégias a partir dos conhecimentos prévios dos alunos:

[...] o erro já não se torna tão marcante e negativo para o aluno, pois ele o encara como algo natural no decorrer da busca pela solução. Nesse processo, o aluno utiliza-se de estratégias próprias baseadas naquilo que já domina ou está aprendendo ainda. Tornando-se o construtor do seu próprio conhecimento, envolve todo seu saber e, se não for suficiente, se interessa por aprender mais, a fim de se tornar o vencedor, bem como aprender a se portar diante de tais competições (Lusmarina, wiki, LM1 -AIV-3).

Branca e Kerusca também ressaltaram a possibilidade de aprendizagem com o erro, não sendo ele mais visto pelos estudantes como algo negativo e permitindo ao professor verificar as compreensões e também as dificuldades que ainda persistem sobre determinado conteúdo matemático.

A análise do erro e do acerto pelo aluno se dá de maneira dinâmica e efetiva, proporcionando a reflexão e a (re)criação de conceitos matemáticos que estão sendo discutidos; o professor tem condições de analisar e compreender o desenvolvimento do raciocínio do aluno e de dinamizar a relação ensino/aprendizagem, por meio de questionamentos sobre as jogadas realizadas pelos jogadores (Branca; Kerusca, wiki, LM1 - AIV-3).

Educação \& Realidade, Porto Alegre, v. 39, n. 4, p. 1113-1133, out./dez. 2014.1125

Disponível em: <http://www.ufrgs.br/edu_realidade> 
Concepções de Matemática de Alunas-Professoras dos Anos Iniciais

A partir desses trechos, identificamos que a concepção de matemática como certo ou errado, revelada pelas alunas-professoras na narrativa inicial, tem dado lugar à dúvida, ao erro, que começa a perder o sentido negativo, para ser visto como uma possibilidade de aprendizagem, como destacou Lusmarina. Branca e Kerusca ressaltaram que o erro permite ao professor verificar as compreensões e as dificuldades apresentadas pelos estudantes.

Cury (2008) questiona se, de fato, os acertos mostram o que o aluno sabe e os erros, apenas o que ele não sabe. E explicita que, mais que isso, suas produções permitem detectar a maneira como eles pensam e também as influências de suas aprendizagens anteriores. Por isso, além de permitir identificar as compreensões e as dificuldades, como apontaram as alunas-professoras, o erro possibilita apreender a forma como os estudantes estão pensando e, portanto, as estratégias que poderão ser empregadas para resolver um exercício ou um problema. Ao reconhecerem que os estudantes têm modos diferentes de pensar e de resolver os problemas, elas (re)dimensionaram a concepção que tinham de matemática como uma ciência exata, com procedimentos únicos.

Dessa forma, segundo a autora “[...] analisar as produções é uma atividade que traz, para o professor e para os alunos, a possibilidade de entender, mais de perto, como se dá a apropriação do saber pelos estudantes" (Cury, 2008, p. 13). Com isso, o professor pode planejar suas ações de modo a solucionar possíveis incompreensões, dificuldades etc.

Além disso, consideramos que as discussões abordadas nas atividades sobre os conteúdos matemáticos levaram a reflexões e problematizações sobre as operações aritméticas; aos conceitos e significados de número; ao conceito de fração e às ideias de grandeza discreta e contínua; e à relação entre fração, número decimal e porcentagem.

Renata discutiu algumas concepções de matemática em um texto individual elaborado na LM1, a partir de uma entrevista ${ }^{3}$ sobre as operações aritméticas com uma professora dos anos iniciais de uma escola. Renata explica que a professora entrevistada ensinava as operações por repetição de técnicas operatórias e os estudantes deveriam resolver muitos exercícios para compreenderem os conceitos de adição e subtração. E complementou:

A professora não relatou a utilização de situações-problema contextualizadas, por exemplo, ao definir a quantidade de alunos tendo a soma de meninos e meninas que estão presentes na sala ou a definição de quantos alunos faltaram, tendo a quantidade de alunos presentes e a quantidade de alunos matriculados na sala. Diante desses relatos acredito que o princípio de proporcionar a justificativa de uma situação problema, ao utilizar uma operação matemática, fica a desejar, uma vez que não há a utilização de situações-problema contextualizadas, apenas a repetição de exercícios de adição e subtração (Texto individual, LM1 - AIV-2).

1126 Educação \& Realidade, Porto Alegre, v. 39, n. 4, p. 1113-1133, out./dez. 2014. Disponível em: <http://www.ufrgs.br/edu_realidade> 
Renata apresentou dois aspectos interessantes, ao argumentar sobre a forma como a professora entrevistada trabalhava as operações: o primeiro, relacionado ao ensino das operações por meio da solução de muitas contas de adição e subtração, ou seja, pela repetição, o que demonstra a concepção de matemática dessa professora de que, para aprender, é preciso memorizar fórmulas e algoritmos, de forma a aplicá-los mecanicamente, em detrimento da compreensão e da justificativa dos processos envolvidos. O segundo se refere à concepção de matemática de Renata, que se coloca contrária à prática da professora, demonstrando que discorda dessa postura e está de acordo com os aspectos da resolução de problemas que levem à necessidade das operações (Chacón, 2000).

Para Branca, as operações deveriam ser ensinadas com metodologias diferentes, em que se priorizasse compreender por que tais procedimentos são realizados sem a ênfase nas regras e nas fórmulas: "Assim a aprendizagem das operações fundamentais deve antes de tudo ser apresentada pelo professor ao aluno de diferentes formas, com metodologias diferenciadas, sobrepondo-se às regras e técnicas memorizadas" (Branca, Texto individual, LM1 - AIV-1).

Segundo Branca, o ensino de matemática pela professora entrevistada seguia uma sequência predeterminada, em que se definia a operação, se ensinava a técnica e, depois, os alunos resolviam muitos exercícios, em que apenas era preciso utilizar o algoritmo. As operações

[...] eram ensinadas de uma forma mais quantitativa e não qualitativa por meio de uma sequência, em que primeiramente era definida a operação, depois se ensinava a técnica, ou seja, o processo pelo qual resolvê-la, para depois aplicar exercícios de fixação ou aplicações relacionadas a esta operação (Branca, texto individual, LM1 - AIV-4).

Pesquisas indicam que a ênfase do ensino de matemática nos aspectos quantitativos faz com que os estudantes, apesar de resolverem as contas, não obtenham sucesso na resolução de problemas, pois sabem apenas utilizar as técnicas operatórias. Por isso, os alunos não conseguiam interpretar o que era solicitado no problema e esperavam o professor dizer qual operação deveriam efetuar. Assim, eles se tornavam meros reprodutores de técnicas e regras, sem compreenderem a própria conta - o funcionamento do algoritmo - e sem desenvolverem um raciocínio crítico e reflexivo.

Essa perspectiva de ensino de matemática é denominada por Lima (1998) de "pedagogia do treinamento", em que os professores explicam o conteúdo, resolvem alguns exemplos na lousa, propõem que os alunos façam uma enorme lista de exercícios e depois reproduzam exatamente essa mesma forma na avaliação, que normalmente é uma prova escrita. Esses quatros momentos - mostrar o conceito, mostrar seu funcionamento, treinar e avaliar - fazem parte dessa pedagogia, que é caracterizada pela aprendizagem do saber fazer e, “[...] por não

Educação \& Realidade, Porto Alegre, v. 39, n. 4, p. 1113-1133, out./dez. 2014.1127

Disponível em: <http://www.ufrgs.br/edu_realidade> 
Concepções de Matemática de Alunas-Professoras dos Anos Iniciais

implicar pensamento, acontece simplesmente pela manipulação das regras da operacionalidade do conceito, do treinamento no mecanismo algorítmico". E essa concepção enfatiza o saber fazer operacional, em detrimento do saber pensar conceitual, implicando "[...] a contra aprendizagem matemática, na sua substituição por uma ação de condicionamento" (Lima, 1998, p. 99 e p. 98).

Além das operações aritméticas, as alunas-professoras abordaram também o conceito de número. Em uma produção textual individual da disciplina de LM1, elas relataram exemplos da importância dos números e levantaram questionamentos de onde eles podem ser encontrados em nosso cotidiano, a partir das indagações: Para que servem os números? Imagine um mundo sem números. Como ele seria? Destacamos os excertos de Alice e de Branca.

Onde quer que estejamos, nossa idade, telefone, documentos, sapatos, ônibus, dinheiro, casa, em tudo os números estão presentes, eles organizam, classificam, ordenam, são utilizados até para o misticismo. Quando reconhecemos a utilização do número em nosso contexto diário, percebemos o quão importante eles são. A hora que acordamos, o dia em que estamos, o mês, o ano, a leitura e a escrita numérica, a sequência [...] (Alice, Texto individual, LM1 - AIII-1).

Compreendo que o número não é apenas um objeto da matemática usado para descrever quantidade, ordem ou medida, enfim, os números vão muito além, pois estão presentes no nosso dia a dia, e tornaram-se tão comuns que nem pensamos mais sobre eles, mas representam muito mais do que uma forma de se medir ou quantificar o que existe ao nosso redor. Por exemplo, utilizamos os números a todo o momento, não somente para contar, até mesmo porque eles estão presentes em tudo o que fazemos, como: no dia, na hora, num endereço, numa placa de carro, numa medida, quantidade, entretanto, nossas práticas estão diretamente relacionadas com o sistema numérico, que no momento não consigo mencionar qualquer ação que não envolva este sistema (Branca, Texto individual, LM1 - AIII-1).

A atividade sobre o conceito de número, realizada por meio do texto individual, em que perguntaram para que servem os números e também propuseram imaginar um mundo sem eles, possibilitou perceberem as muitas utilidades e as inúmeras situações nas quais são usados os números e as diferentes ideias de quantidade, medida, identificação, código etc.

Além disso, as alunas-professoras destacaram também o conceito de fração, em um texto, elaborado individualmente na disciplina LM2, que aborda esse conteúdo como sendo a síntese de duas ideias: quantidade e medida. Aqui expomos o que relatou Branca:

Falar de fração não é tão simples como parece, pois embora ela seja a ampliação dos conjuntos numéricos, representam um novo tipo de número que não é fácil compreender, já que suas ideias básicas são relacionadas

1128 Educação \& Realidade, Porto Alegre, v. 39, n. 4, p. 1113-1133, out./dez. 2014 Disponível em: <http://www.ufrgs.br/edu_realidade> 
com quantidade e medida. Assim uma fração não são dois números, mas sim uma relação expressa por eles (Texto individual, LM2 - AIII-1).

Esse mesmo aspecto é indicado por Renata, ao explicitar que “[...] essa representação demonstra relações matemáticas diferentes das que se encontram nos números naturais, já que é a síntese de duas ideias expressas, em dois números: a quantidade e a medida" (Texto individual, LM2 - AIII-1)

Ressaltaram também os aspectos relativos a grandeza discreta e contínua. Andréia e Ana destacaram o significado de cada uma dessas grandezas e apresentaram exemplos, fazendo referência ao material impresso utilizado nas disciplinas.

O autor [do material impresso] destaca ainda que existem dois tipos de grandezas medidas pelas frações as grandezas contínuas como um pedaço de papel que pode ser dividido em infinitas partes; e as grandezas discretas, como um conjunto de pessoas em que existe um número limitado de frações que podem ser representadas. Como exemplo um grupo de 12 pessoas só pode representar uma fração que seja divisor de 12, pois não podemos partir uma pessoa ao meio para representar por exemplo 2/5 (Andréia, Texto individual, LM2 - AIII-1).

O autor [do material impresso] nos apresenta duas ideias a respeito de fração: as grandezas contínuas e as grandezas discretas. A primeira pode ser representada por qualquer fração, enquanto a segunda, somente por algumas. As tiras de cartolina ou chocolates são exemplos de grandezas contínuas e um conjunto de objetos ou de figurinhas são exemplos de grandezas discretas (Ana, Texto individual, LM2 - AIII-1).

Nesses trechos apresentados, as alunas-professoras abordaram diferentes aspectos dos conteúdos matemáticos ensinados nos anos iniciais do Ensino Fundamental: operações, número e fração. Sobre as frações, elas destacaram o conceito e as ideias de grandeza discreta e contínua. Essas discussões ocorreram devido ao material e às atividades propostas que trabalham esses conteúdos.

Dessa forma, as alunas-professoras podem ter construído conceitos matemáticos que não sabiam ou, mesmo, tê-los ressignificado, pois elas tiveram que mobilizar seus conhecimentos específicos do conteúdo para argumentar, opinar, discutir as ideias do referencial teórico, o que pode ter promovido aprendizagens.

Podemos identificar um exemplo de aprendizagem no trecho em que Andréia discute sobre as grandezas contínuas, pois ela apresenta um exemplo que não foi abordado no material impresso das disciplinas: “[...] as grandezas contínuas como um pedaço de papel que pode ser dividido em infinitas partes" (Texto individual, LM2 - AIII-1).

O contato com esses conceitos por meio do material e das atividades realizadas pode ter promovido alguns estranhamentos sobre esses conteúdos matemáticos, proporcionando reflexões. Um exemplo claro 
Concepções de Matemática de Alunas-Professoras dos Anos Iniciais

é a surpresa relatada por Renata, no fórum de discussão sobre os problemas que envolviam fração, ao descobrir a relação entre fração e porcentagem: ai, ai, ai, ai!!!! Para tudo!!!! Acho que quero descer!!!!!! rs. Fiquei feliz por ter conseguido acertar o primeiro problema...Ufa. Mas, nunca imaginei que se no enunciado estava em número fracionário eu pudesse pensar em porcentagem (Fórum de discussão, LM2 - AIII-2).

A partir dessas discussões, podemos perceber que emergem diferentes aspectos relacionados às concepções de matemática, como a matemática na perspectiva da constituição da cidadania; outra maneira de ver o erro; diversas estratégias para ensinar matemática; os conteúdos matemáticos que se distanciam das lembranças que apresentaram na narrativa sobre sua trajetória escolar.

\section{Algumas Considerações}

Tivemos como objetivo, neste artigo, discutir as concepções sobre matemática de alunas-professoras dos anos iniciais do Ensino Fundamental de um curso de Pedagogia à distância.

As alunas-professoras apresentaram várias características da concepção de matemática pautada na resolução de problemas, na qual há necessidade de justificar e compreender as fórmulas, os procedimentos e os algoritmos, em detrimento da simples reprodução a partir da memorização. Contudo, elas destacaram que a memorização é importante, mas que a aprendizagem deve ir além desse aspecto.

Além disso, ressaltaram que a matemática faz parte da constituição da cidadania, pois implica na concepção de mundo dos alunos e pode desenvolver a criticidade e a reflexão ou a passividade e alienação. Ainda, a matemática permite a tomada de decisão em relação a problemas referentes tanto à própria matemática como à vida.

O ensino de matemática deve ser permeado por diferentes metodologias e ter como foco a argumentação e a exploração. Nesse sentido, o erro é apresentado com a perspectiva de uma possibilidade de aprendizagem e, para o professor, como uma forma de perceber as lacunas e as dificuldades dos alunos para avançar na construção de seu conhecimento.

O estudo dos diferentes conceitos matemáticos abordados nas disciplinas fez com que as alunas-professoras refletissem e problematizassem o ensino desses conceitos e permitiu-lhes compreender muitos deles. Esse último aspecto é evidenciado na surpresa de Renata, ao descobrir a relação entre a fração e a porcentagem.

As reflexões das alunas-professoras mostraram sua preocupação com a forma como aprenderam matemática, o que, de certo modo, influenciou sua concepção a respeito da disciplina. E, por entenderem não ser mais suficiente essa forma de ensinar, buscaram alternativas para romper com a concepção de matemática utilitária e platônica.

1130 Educação \& Realidade, Porto Alegre, v. 39, n. 4, p. 1113-1133, out./dez. 2014 Disponível em: <http://www.ufrgs.br/edu_realidade> 
Essa preocupação e essa nova postura didática podem fazer com que as alunas-professoras, em suas práticas de sala de aula, se enveredem por outros caminhos.

Não é possível afirmar que essas mudanças tenham provocado modificações na prática docente, pois Thompson (1992) relatou vários estudos em que se discutiam se as concepções estariam ou não de acordo com a prática de ensino dos professores. Dessa forma, a prática e as concepções, para a autora "[...] sugerem uma complexa relação, com muitas origens de influência no trabalho: uma origem é o contexto social no qual o ensino da matemática tem lugar, com todas as restrições que impõe e as oportunidades que oferece" (Thompson, 1992, p. 138).

Assim, de acordo com Ponte não é fácil promover mudanças nas concepções de um indivíduo, principalmente quando ele não está empenhado em realizá-las e, além disso, mudanças profundas ocorrem apenas,

[...] perante abalos muito fortes, geradores de grandes desequilíbrios. Isto apenas sucede no quadro de vivências pessoais intensas, como a participação num programa de formação altamente motivador ou em experiências com forte dinâmica de grupo, mudança de escola, de profissão (Ponte, 1992, p. 27).

Nessa perspectiva, a partir dos dados analisados, temos indícios de que ocorreram pequenas mudanças nas concepções, que, de certa forma, podem refletir em algumas práticas das alunas-professoras. Mas não podemos afirmar que essas mudanças tenham sido profundas ou que tenham tido um forte impacto na prática docente.

Compreendemos que as mudanças de concepção não se fazem a partir de uma única experiência do professor - por exemplo, somente no trabalho com as disciplinas do curso de Pedagogia -, pois constituem um processo complexo e permeado por diferentes fatores, que pode ser comparado ao que ocorre a um copo enchendo-se de água. As reflexões e as problematizações podem ter provocado incômodos que levaram a pequenas modificações das concepções, processadas paulatinamente, à medida que os docentes participam de diferentes espaços formativos - cursos de curta duração, congressos, palestras, oficinas, pós-graduação, grupos de estudo, horários de formação coletiva na escola, na sala de aula etc.

A quantidade de água acrescentada por cada uma das experiências do professor, nesses espaços, depende dos abalos causados por elas: fortes abalos acrescentam mais água que aqueles superficiais, podendo haver, inclusive, alguns que não acrescentem nada ou, ainda, até retirem água desse copo. Um exemplo de uma formação que não acrescenta ou que retira água do copo pode ser uma palestra em que, pelos mais diferentes motivos - o palestrante não consegue prender a atenção, o professor está participando obrigado ou o assunto não o interessa-, não

Educação \& Realidade, Porto Alegre, v. 39, n. 4, p. 1113-1133, out./dez. 2014.1131 Disponível em: <http://www.ufrgs.br/edu_realidade> 
Concepções de Matemática de Alunas-Professoras dos Anos Iniciais

deixa o professor com interrogações que o levem a refletir e a tomar sua prática como objeto dessa reflexão.

Quando o copo transborda, provoca mudanças nas concepções do professor, ou seja, não é um aspecto isolado o responsável por essa mudança, mas um conjunto de fatores - toda a água do copo. Uma experiência pode ser o estopim para iniciar essa transformação, mas ela não consegue fazer isso isoladamente; por isso, não é imediata.

Ao transbordar, deixa espaço para um pouco mais de água; assim, toda a água que continua no copo - todas as concepções - vai influenciar e ser influenciada pelas novas experiências do professor, que provocaram esse movimento. Ainda, a água que transbordou também não deixa de exercer influência no restante que continua no copo.

Temos clareza de que os modelos e/ou as metáforas têm suas limitações e não conseguem explicitar toda a complexidade desse processo, mas nos ajudam a pensar a respeito dele.

Contudo, queremos mostrar que as reflexões e as problematizações provocadas pelas disciplinas de LM1 e LM2 são indícios de pequenas mudanças nas concepções; ou ainda poderão ser o estopim de um processo que pode ter se iniciado há um tempo e que se consolidará apenas a partir de várias experiências de formação que provoquem no professor reflexões, inquietações e questionamentos.

Recebido em 24 de março de 2014 Aprovado em 19 de maio de 2014

\section{Notas}

1 A ferramenta wiki possibilita a construção de um texto coletivo por diversos estudantes e registra as modificações realizadas por cada um deles.

2 Jogo de tabuleiro em que, nas casas, há diferentes números. É jogado por duas equipes alternadamente: cada uma, na sua vez, joga o dado e constrói uma divisão, na qual o dividendo é o número da casa onde está sua ficha e o divisor, o número que sai no dado. O resto da divisão indica quantas casas o jogador irá movimentar sua ficha.

3 Uma das atividades da LMI era realizar uma entrevista com professor (a) dos anos iniciais, procurando entender como era o trabalho dele(a) com as quatro operações.

\section{Referências}

BARDIN, Laurence. Análise do Conteúdo. Lisboa: Edições 70, 1977.

BOGDAN, Robert C.; BIKLEN, Sari K. Investigação Qualitativa em Educação: uma introdução à teoria e aos métodos. Porto: Porto Editora, 1994.

CHACÓN, Inés M. G. Matemática Emocional: los afectos en el aprendizaje matemático. Madrid: Narcea, 2000.

1132 Educação \& Realidade, Porto Alegre, v. 39, n. 4, p. 1113-1133, out./dez. 2014 Disponível em: <http://www.ufrgs.br/edu_realidade> 
CURY, Helena N. Análise de Erros: o que podemos aprender com as respostas dos alunos. Belo Horizonte: Autêntica, 2008.

FIORENTINI, Dario; LORENZATO, Sergio. Investigação em Educação Matemática: percursos teóricos e metodológicos. Campinas: Autores associados, 2006.

LIMA, Luciano C. Da Mecânica do Pensamento ao Pensamento Emancipado da Mecânica. Programa Integrar, Caderno do Professor, Trabalho e Tecnologia, CUT/SP, 1998. P. 95-103.

LORENZATO, Sérgio. Porque não Ensinar Geometria? A Educação Matemática em Revista, Recife, v. 3, n. 4, p. 3-13, 1995.

LÜDKE, Menga; ANDRÉ, Marli E. D. A. Pesquisa em Educação: abordagens qualitativas. São Paulo: EPU, 1986.

NACARATO, Adair M.; MENGALI, Brenda L. S.; PASSOS, Cármem L. B. A Matemática nos anos Iniciais do Ensino Fundamental: tecendo fios do ensinar e do aprender. Belo Horizonte: Autêntica, 2009.

PONTE, João P. Concepções dos Professores de Matemática e Processos de Formação. In: PONTE, João P. (Org.). Educação Matemática: temas de investigação. Lisboa: IIE, 1992. P. 185-239.

SERRES, Fabiana F. Concepção e Prática do Ensinar Matemática nos Anos Iniciais do Ensino Fundamental: estudo de caso em um curso de Pedagogia a distância. 2010. 104 f. Dissertação (Mestrado em Educação) - Faculdade de Educação, Universidade Federal do Rio Grande do Sul, Porto Alegre, 2010.

THOMPSON, Alba G. Teachers' Beliefs and Conceptions: a synthesis of the research. In: GROUWS, Douglas A. Handbook of Research on Mathematics Teaching and Learning. New York: Macmillan Publishing Company, 1992. P. 127146.

VIGNOTO, Juliana; MORAES, Silvia P. G. A Concepção de Matemática nos Primeiros anos de Escolarização: uma análise sobre os cadernos dos escolares. In: ENCONTRO NACIONAL DE EDUCAÇÃO MATEMÁTICA, 11., 2013, Curitiba. Anais... Curitiba, 2013. P. 1-15.

VIÑAO FRAGO, Antonio. Por una Historia de la Cultura Escolar: enfoques, cuestiones, fuentes. In: CONGRESO DE LA ASOCIACIÓN DE HISTORIA CONTEMPORÁNEA, 3, 1998, Valladolid - España. Anais... Valladolid - España, 1998. P. 167-183. Disponível em: <http://www.ahistcon.org/docs/Valladolid.pdf >. Acesso em: 11 ago. 2012.

Reginaldo Fernando Carneiro é doutor em Educação (UFSCar), docente da Faculdade de Educação e do Programa de Pós-Graduação em Educação Matemática da UFJF atuando no mestrado profissional. Coordena o Grupo de Estudos e Pesquisas em Educação Matemática (GREPEM) da UFJF.

E-mail: reginaldo.carneiro@ufjf.edu.br

Cármen Lúcia Brancaglion Passos é doutora em Educação: Educação Matemática (Unicamp), docente Departamento de Teorias e Práticas Pedagógicas e do Programa de Pós-Graduação em Educação da UFSCar. Coordena o Grupo de Estudos e Pesquisas em Educação Matemática (GEM) da UFSCar. E-mail: carmen@ufscar.br

Educação \& Realidade, Porto Alegre, v. 39, n. 4, p. 1113-1133, out./dez. 2014.1133 Disponível em: <http://www.ufrgs.br/edu_realidade> 